\title{
Interactive comment on "Autonomous Airborne Mid-IR Spectrometer for High Precision Measurements of Ethane during the NASA ACT-America Studies" by Petter Weibring et al.
}

Petter Weibring et al.

petter.weibring@colorado.edu

Received and published: 18 September 2020

The comment was uploaded in the form of a supplement:

https://amt.copernicus.org/preprints/amt-2020-210/amt-2020-210-AC2-

supplement.pdf

Interactive comment on Atmos. Meas. Tech. Discuss., doi:10.5194/amt-2020-210, 2020. 